\title{
The psychosocial environment at work: an assessment of the World Health Organization Regional Office for the Eastern Mediterranean
}

A. Jain, ${ }^{1}$ K. Saeed, ${ }^{2}$ S. Arnaout ${ }^{3}$ and E. Kortum ${ }^{4}$

\begin{tabular}{|c|}
\hline 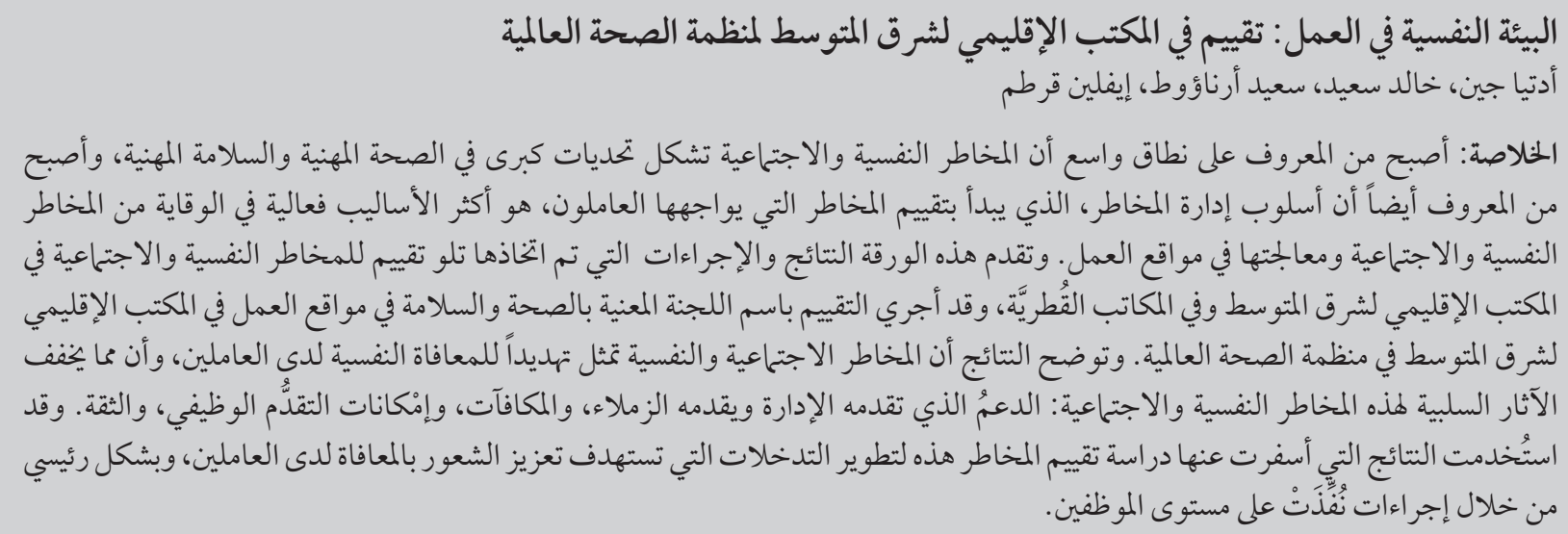 \\
\hline
\end{tabular}

ABSTRACT Psychosocial risks are widely recognised as major challenges to occupational health and safety. The risk management approach, which starts with an assessment of the risk that they pose, is acknowledged as the most effective way of preventing and managing psychosocial risks at the workplace. This paper presents the findings and action taken following a risk assessment of psychosocial risks, at the World health Organization Regional Office for the Eastern Mediterranean (EMRO) and country offices, carried out on behalf of the Committee on Health and Safety in the Workplace in EMRO. The findings show that psychosocial risks pose a threat to the mental well-being of staff. Management and co-worker support, rewards, possibilities for development, and trust mitigate the negative impact of psychosocial risks. The results of this risk assessment are being used to develop interventions aimed at enhancing the sense of well-being of staff, initially through actions at the employee level.

Environnement psychosocial au travail : évaluation par le Bureau régional de l'Organisation mondiale de la Santé pour la Méditerranée orientale

RÉSUMÉ Les risques psychosociaux sont largement reconnus comme des obstacles majeurs à la santé et la sécurité au travail. L'approche de gestion des risques, qui débute par l'évaluation des risques posés, est reconnue comme la méthode la plus efficace pour prévenir et prendre en charge les risques psychosociaux en milieu professionnel. Le présent article a étudié les résultats d'une évaluation des risques psychosociaux menée pour le Comité santé et sécurité au travail et les actions qui ont suivi au Bureau régional de l'Organisation mondiale de la Santé pour la Méditerranée orientale et dans les bureaux de pays. Les résultats indiquent que les risques psychosociaux représentent une menace pour le bien-être mental du personnel. L'appui fourni par la direction et les collègues, les éloges, les possibilités de développement personnel et professionel et la confiance limitent l'impact négatif des risques psychosociaux. Les résultats de l'évaluation des risques sont en cours d'exploitation pour élaborer des interventions destinées à améliorer le sentiment de bien-être du personnel, au moyen d'actions au niveau des employés.

'Nottingham University Business School, Nottingham, United Kingdom (Correspondence to A. Jain: Aditya.Jain@nottingham.ac.uk). ${ }^{2}$ Mental Health and Substance Abuse; ${ }^{3}$ Health for Special Groups, World Health Organization Regional Office for the Eastern Mediterranean, Cairo, Egypt.

${ }^{4}$ Occupational Health, Interventions for Healthy Environments, Department of Public Health and Environment, World Health Organization, Geneva, Switzerland.

Received: 16/06/10; accepted: 03/11/10 


\section{Introduction}

Health is defined not merely as the absence of disease or infirmity but a state of complete physical, mental and social well-being [1]. Similarly a healthy working environment is defined not only by absence of conditions potentially leading to disease or infirmity but by presence of conditions promoting wellbeing [2]. Such conditions relate to the psychosocial environment at work, which is determined by an interaction between organizational environment and structures on one hand and work content, and employees' competencies and needs on the other [3]. Risks to the psychosocial environment can stem from an imbalance between job content, workload and work pace, work schedule, control at work, environment and equipment, organizational culture and function, interpersonal relationships at work, role in organization, career development, and home-work interface, collectively referred to as psychosocial risks [4]. Psychosocial risks, also commonly referred to as organizational stressors, have been defined as those aspects of the design and management of work and its social and organizational contexts that have the potential for causing psychological or physical harm [5].

Work-related psychosocial risks lead to workplace problems as workrelated stress, workplace violence and bullying [4]. Work-related stress has been defined as "... a pattern of emotional, cognitive, behavioural and physiological reactions to adverse and noxious aspects of work content, work organization and work environment. It is a state characterized by high levels of arousal and distress and often by feelings of not coping" [6]. The term work-related violence refers to incidents where persons are abused, threatened or assaulted in circumstances related to their work, involving an explicit or implicit challenge to their safety, well-being and health. Bullying or harassment occurs when 1 or more workers or managers are abused, humiliated or assaulted by colleagues or superiors [7].

Psychosocial risks and related workplace problems such as workrelated stress, workplace violence and bullying are now widely recognized major challenges to occupational health and safety [8], with a large body of research indicating that these risks lead to vast financial losses $[9,10]$ in addition to the potentially greater societal and personal costs. Exposure to psychosocial risks in the workplace have been demonstrated to have a possible detrimental impact on workers' physical, mental and social health $[11,12]$. In addition, a growing body of evidence indicates both a direct and indirect role of the psychosocial working environment (through mediators such as work-related stress, bullying, harassment) on organizational health indices (such as absenteeism, sickness absence, productivity, job satisfaction and intention to quit) $[12,13]$.

Work stress can cause different kinds of problems at the individual level. Numerous studies have indicated that stress at work is associated with heart disease, depression, and musculoskeletal disorders and there is consistent evidence that high job demands, low control, and effort-reward imbalance are risk factors for mental and physical health problems [13], thereby leading to further strain on public spending for increased costs on healthcare. At the organizational level, work stress can lead to a deteriorated work climate, and can have an impact on product and service quality as well as the image of the organization. Research suggests that between $50 \%$ and $60 \%$ of all lost working days have some link with work-related stress leading to significant costs to companies as well as to society in terms of both human distress and impaired economic performance [12].
Exposure to harassment, bullying and violence at work are also acknowledged as significant social stressors resulting in different kinds of symptoms of self-reported ill-health and stress symptoms. The link between bullying and physical, mental and psychosomatic health symptoms is well established. These symptoms include, stress, depression, reduced self-esteem, self-blame, phobias, sleep disturbances, digestive and musculoskeletal problems. Consequences to the organization also include increased complaints, grievance, costs of litigation, and staff turnover as well as a decrease in the motivation, satisfaction and productivity of the workers, and damage to the company image with a loss in public goodwill and reputation [14].

Due to globalization and changes in the nature of work, these risks are also increasingly prevalent in developing countries. While in industrialized countries people are becoming more aware of the harmful effects of psychosocial risks such as work-related stress and are consequently learning how to prevent and manage it $[4,15]$, in developing countries there are still not enough indepth studies.

Particular challenges in relation to psychosocial risks and their management exist both at the organization level and at the macro level. On the enterprise level, there is a need for systematic and effective policies, clearly linked to management practices, to prevent and control the various psychosocial risks at work. On the national and macro level, the main challenge is to translate existing policies into effective practice through the provision of tools that will stimulate and support organizations to undertake that challenge, thereby preventing and controlling psychosocial risks in the workplace and society alike [16].

Even though researchers, practitioners, government bodies and organizations differ in awareness and understanding of these new types of 
challenges in working life, it is widely accepted that the risk management approach, adapted to the management of psychosocial risks, is an ideal method to prevent harm generated from these hazards. Consequently, a number of approaches based on the risk management paradigm have been developed and implemented [17].

Risk assessment is a central element of the risk management process [12], and the most utilized instrument in identifying stress factors and stress problems is the self-report questionnaire [18]. This article reports the findings of a survey to assess the psychosocial well-being of employees at the World Health Organization (WHO) Regional Office for the Eastern Mediterranean (EMRO) and their perception of the factors affecting it. The results of the survey are being used to suggest interventions aimed at enhancing the sense of psychosocial well-being of the members through recommended actions at the individual, group and organization levels.

\section{Methods}

\section{Participants and procedure}

A total of 185 employees from the WHO Eastern Mediterranean Region took part in the survey. The survey was carried out between 2 and 23 August 2009 (a 3-week period) in coordination with the health and safety committee at EMRO. A 3-week period was allowed for respondents to complete and submit the questionnaires. An online version of the questionnaire was developed using Datacol (on the WHO extranet). Employees were invited on behalf of the Committee on Health and Safety in the Workplace in EMRO to participate in the survey by direct email. The invitation was also posted on the EMRO intranet and bulletin board. The target sample was all employees at EMRO ( $n$ $=950$ ).
Participation was voluntary and the data collected through the online questionnaire was anonymous and confidential. Participants were also given assurances that no individual employee would be identifiable through any of the reports or related publications. A 19\% response rate was achieved (Total population: 950 employees). Rationale for the low response rate is presented in the Discussion.

\section{Measure used}

The survey was conducted using the medium version of Copenhagen Psychosocial Questionnaire II [19], which is a comprehensive instrument developed for assessment of the psychosocial work environment.

The questionnaire used comprised 24 dimensions related to different levels of analysis (organization, department, job, person-work interface, and individual), work-tasks, the organization of work, interpersonal relations at work, cooperation and leadership. The questionnaire also covers potential work stressors as well as resources such as support, feedback, commitment, and good health. The internal reliability of each dimension ranges from $a=0.71$ to $\alpha=0.93$.

\section{Results}

Overall, 185 employees took part in the survey, of whom 115 were based at EMRO and 70 in the Country Offices; 73 respondents worked at the professional level while 112 worked at the general level; 112 employees had fixed contracts and 70 had short term/ temporary contracts while 3 respondents worked in the non-staff category; 69 respondents were male and 116 were female. The age of the participants ranged from under 30 years to over 60 years: $29.2 \%$ were below 30 years of age, $31.5 \%$ were aged $31-39$ years, while $22.5 \%$ were 60 years or over.
All of the 185 respondents (19\% response rate) completed the questionnaire in full, i.e. no parts were incomplete.

Results on the individual dimensions of the questionnaire were compared with normative data of Danish employees $(n=3517)$ [19], using $t$-test analysis. The findings clearly indicate a number of statistically significant differences (Table 1 ). The participants reported higher than average scores on most dimensions of the questionnaire, such as greater demands at work, fewer opportunities for development and communication, greater work-family conflict and lower job satisfaction, consequently leading to greater rates of work-related stress and burn-out and poorer selfreported health when compared with normative data [19].

Pearson product-moment correlation was used to further analyse the relationship between 28 dimensions of the questionnaire: Table 2 presents the findings for the key dimensions related to psychosocial risks and individual health.

A number of significant relationships were found to exist between the dimensions. Analysis of variance was further used to test for differences between groups, based on location of work (regional office or country office), age, job role (professional level or general level), gender and type of contract (fixed term, short term or non-staff). The analysis revealed significant differences between staff based in country offices compared with staff based in the regional office. Staff in the country offices reported greater influence at work: $\mathrm{F}(1184)=$ 9.55, $P<0.01$, better possibilities for development: $\mathrm{F}(1184)=9.34, P<0.01$, greater recognition and appreciation (rewards) by management: $\mathrm{F}(1184)=$ $6.95, P<0.01$, greater job satisfaction: $F(1184)=7.63, P<<0.01$ and greater vertical trust (employees trust towards management): $F(1184)=11.11$, 


\begin{tabular}{|c|c|c|c|c|c|c|}
\hline \multirow[t]{2}{*}{ Psychosocial dimension } & \multicolumn{2}{|c|}{$\begin{array}{l}\text { Normative data } \\
\quad(n=3517)\end{array}$} & \multicolumn{2}{|c|}{$\begin{array}{l}\text { EMRO sample } \\
\qquad(n=185)\end{array}$} & \multicolumn{2}{|c|}{ Comparison ( $t$-test) } \\
\hline & Mean & SD & Mean & SD & $t$ & df \\
\hline Quantitative demands & 40.23 & 20.51 & 44.56 & 17.56 & $3.31^{* *}$ & 184 \\
\hline Workplace: tempo & 59.52 & 19.10 & 70.83 & 15.72 & $9.61^{* *}$ & 184 \\
\hline Emotional demands & 40.77 & 24.35 & 49.79 & 17.92 & $6.71^{* *}$ & 184 \\
\hline Influence at work & 49.80 & 21.23 & 43.22 & 18.35 & $-4.77^{* *}$ & 184 \\
\hline Possibilities for development & 65.91 & 17.59 & 60.28 & 19.79 & $-3.78^{* *}$ & 184 \\
\hline Meaning of work & 73.79 & 15.82 & 67.41 & 22.88 & $-3.72 * *$ & 184 \\
\hline Commitment to the workplace & 60.94 & 20.41 & 55.86 & 25.41 & $-2.64^{* *}$ & 184 \\
\hline Predictability (communication) & 57.71 & 20.90 & 53.08 & 22.57 & $-2.72^{* *}$ & 184 \\
\hline Rewards & 66.22 & 19.89 & 62.35 & 24.47 & $-2.36^{*}$ & 184 \\
\hline Role clarity & 73.50 & 16.43 & 72.19 & 22.33 & -0.78 & 184 \\
\hline Role conflicts & 42.01 & 16.64 & 49.08 & 17.77 & $5.31^{* *}$ & 184 \\
\hline Quality of leadership & 55.29 & 21.11 & 51.89 & 28.45 & -1.59 & 184 \\
\hline Social support from colleagues & 57.30 & 19.72 & 54.07 & 22.65 & -1.90 & 184 \\
\hline Social support from supervisors & 61.58 & 22.46 & 61.00 & 27.72 & -0.28 & 184 \\
\hline Social community at work & 78.73 & 18.95 & 68.21 & 22.52 & $-6.21^{* *}$ & 184 \\
\hline Job satisfaction & 65.32 & 18.21 & 57.86 & 23.38 & $-4.24^{* *}$ & 184 \\
\hline Work-family conflict & 33.47 & 24.29 & 52.80 & 26.17 & $9.85^{* *}$ & 184 \\
\hline Horizontal trust & 68.61 & 16.92 & 53.93 & 19.85 & $-9.88^{* *}$ & 184 \\
\hline Vertical trust & 67.03 & 17.77 & 52.52 & 20.11 & $-9.61^{* *}$ & 184 \\
\hline Justice and respect & 59.19 & 17.73 & 41.53 & 22.60 & $-10.42^{* *}$ & 184 \\
\hline Self-reported general health & 66.00 & 20.89 & 55.34 & 21.41 & $-6.64^{* *}$ & 184 \\
\hline Sleeping troubles & 21.31 & 19.00 & 39.01 & 23.64 & $9.99 * *$ & 184 \\
\hline Burnout & 33.15 & 18.16 & 54.17 & 23.40 & $11.98^{* *}$ & 184 \\
\hline Stress & 26.72 & 17.71 & 50.03 & 24.83 & $17.32^{* *}$ & 184 \\
\hline
\end{tabular}

${ }^{*} P<0.05 ;{ }^{*} P<0.01$.

$S D=$ standard deviation; $d f=$ degrees offreedom .

$P<0.01$, while the staff at the Regional Office reported higher scores for burnout: $\mathrm{F}(1184)=15.76, P<0.01$ and stress: $\mathrm{F}(1184)=15.71, P<0.01$.

Furthermore the analysis revealed significant differences between younger and older staff only in relation to their scores on the "influence at work" dimension: $\mathrm{F}(4181)=3.79, P<0.01$, post-hoc tests (Tukey HSD and Bonferroni) confirmed that the difference between those aged 40-49 years and those over 60 years was significant [effect size $(\mathrm{d})=0.99$ ] and was unlikely to have arisen by sampling error.

Significant differences between staff in professional roles compared with staff in general roles were also seen.
Professional staff reported greater quantitative demands: $\mathrm{F}(1184)=5.12, P$ $<0.02$, emotional demands: $\mathrm{F}(1184)$ $=6.34, P<0.01$ and greater work-family conflict: $\mathrm{F}(1184)=13.80, P<0.01$ compared with general staff. However, professional staff also reported greater influence at work: $\mathrm{F}(1184)=14.92$, $P<0.01$, better possibilities for development: $\mathrm{F}(1184)=22.14, P<0.01$, and greater rewards: $\mathrm{F}(1184)=5.99$, $P<0.02$.

Significant gender differences were also found. Male employees reported greaterquantitative demands: $\mathrm{F}(1184)$ $=5.85, P<0.02$, greater emotional demands: $\mathrm{F}(1184)=4.58, P<0.05$ and greater work-family conflict: $\mathrm{F}(1184)$
$=5.13, P<0.02$ compared with their female colleagues. However, male employees also reported greater influence at work: $\mathrm{F}(1184)=7.13, P<0.01$, better possibilities for development: $\mathrm{F}(1184)=7.98, P<0.01$ and greater job satisfaction: $\mathrm{F}(1184)=4.30, P$ $<0.05$.

There were also significant differences between permanent and temporary employees. Short-term/temporary staff reported greater recognition and appreciation by management (rewards) $\mathrm{F}(2183)=5.05, P<0.01$ and greater vertical trust: $\mathrm{F}(2183)=6.18$, $P<0.01$ compared with staff on fixed term contracts. Staff on fixed term contracts and non-staff reported 


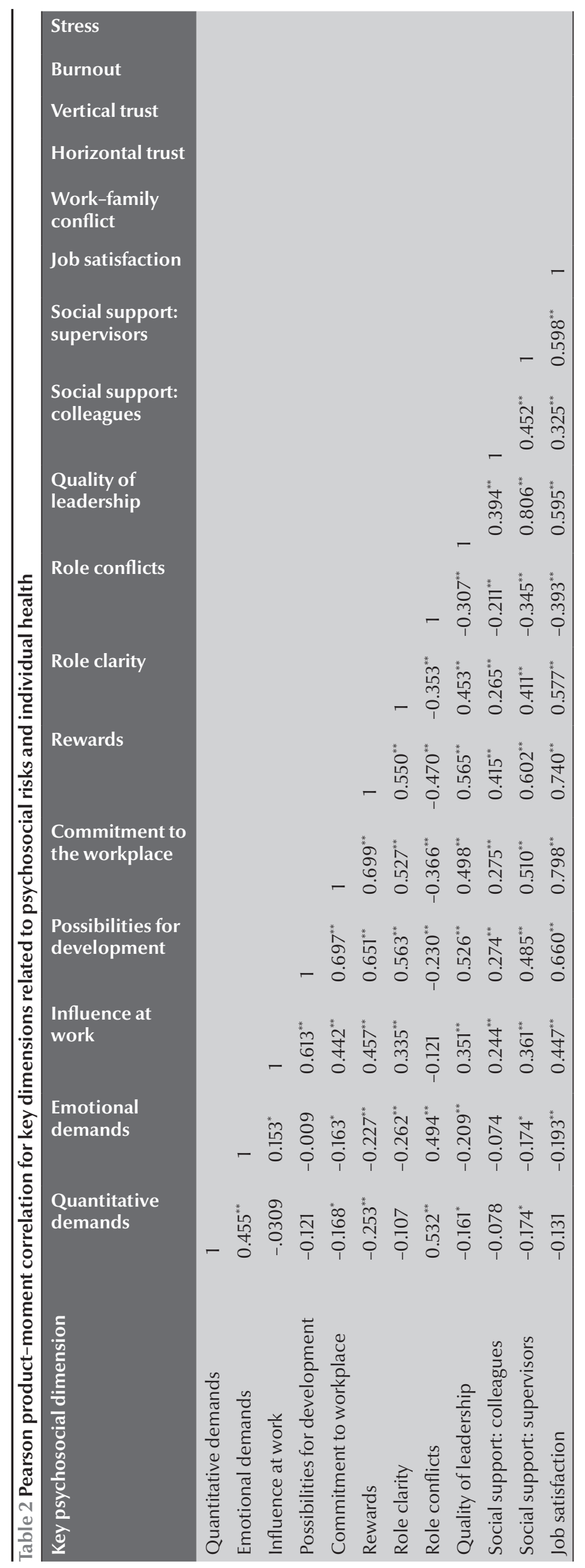

significantly greater role conflict: $\mathrm{F}(2183)=3.02, P$ $<0.05$ and stress: $\mathrm{F}(2183)=4.59, P<0.01$.

Participants also completed questions relating to their experience of violence and bullying at work: $8.4 \%(n=23)$ of the sample reported that they had been exposed to undesired sexual attention at their workplace a few times during the previous 12 months, while $2.8 \%(n=7)$ reported that they were exposed to such attention on a regular basis. Results also indicated that $9.0 \%(n=$ 17) of employees reported they had been exposed to threats of violence at the workplace during the previous 12 months, while $2 \%(n=3)$ had been exposed to physical violence. Incidence of bullying was found to be high, with $20 \%(n=37)$ of the sample reporting that they had been exposed to bullying at the workplace during the previous 12 months; of these $5.4 \%(n=10)$ experienced bullying on a frequent basis.

\section{Discussion}

Work-related psychosocial risks have been identified as one of the major contemporary challenges for occupational health and safety, and are linked to such workplace problems as work-related stress, workplace violence and bullying [6]. Our findings clearly indicated that these risks also pose a challenge to the mental well-being of employees at the regional and country offices in the WHO Eastern Mediterranean Region. The participants reported higher than average scores on most dimensions of the questionnaire, such as greater demands at work, fewer opportunities for development and communication, greater work-family conflict and lower job satisfaction, consequently leading to greater rates of work-related stress and burn-out and poorer self-reported health when compared with normative data [19].

The results also highlighted a number of significant relationships between the various psychosocial risks and stress, burn-out and work-family conflict, which is in accordance with findings of previous research $[4,17]$.

The results must be interpreted with caution in view of the low response rate for the survey. The low response rate was most likely due to the timing of the survey, which was in the summer months when many staffare on annual leave. The low response rate may also be attributed to the lack of trust in senior management from some employees, who may be 
sceptical about the action taken following the survey.

A number of significant differences between various employee groups based on location, age, job role, gender, and contract type highlighted the positive role of management and co-worker support, rewards, possibilities for development and trust (with management as well as colleagues) playing an important role in mitigating the impact of psychosocial risks. Staff in the country offices reported greater influence at work, better possibilities for development, greater recognition and appreciation by management, greater job satisfaction and greater trust towards management. Consequently staff at the country offices reported lower scores on burn-out and work-related stress compared with their colleagues at the Regional Office. These findings can be used to design effective theory based interventions to improve the working environment at the regional office as emphasized by Kompier and Kristensen, who suggest that interventions should theoretically and logically complement, or match the problems that have been identified through the risk assessment [20].

Though our findings revealed significant differences between younger and olderstaffin relation to theirscores on the "influence at work" dimension, it did not seem to affect their experience of stress and burn-out. This is possibly because younger employees do not perceive this as unfair owing to socially accepted norms that senior staff have greater influence at work because of their age and experience. The findings also revealed significant differences between staff in professional roles compared with staff in general roles. Though the professional staff reported greater quantitative demands, emotional demands and greater work-family conflict, they did not report greater stress or burn-out compared with general staff. This is possibly due to the mitigating affect of greater influence at work, better possibilities for development and greater rewards compared with general staff.

The analysis also revealed signifcant differences between permanent and temporary employees. Interestingly, short-term/temporary staff reported greater recognition and appreciation by management and also greater trust towards management compared with staff on fixed term contracts. Consequently staff on temporary assignments reported significantly lower stress than staff on fixed term contracts and non-staff. Greater stress amongst fixed-term staff was further aggravated by greater role conflict. This suggests the need to further explore the causes of such role conflict and design appropriate interventions to address these issues.

We also found significant gender differences. Male employees reported greater quantitative demand, greater emotional demands and greater work-family conflict compared with their female colleagues. However, male employees also reported greater influence at work, better possibilities for development and greater job satisfaction, thereby mitigating the harmful effects of greater demands and work-family conflict. Therefore, no differences were found between scores on stress and burn-out. Similar findings have also been reported in other studies since men and women tend to work in very different jobs and in different occupational sectors [21] resulting in differential exposure to workplace hazards and impacts on occupational health and well-being [22].

\section{Conclusion: actions and future directions}

The results of this initial risk assessment for psychosocial risks at WHO EMRO clearly indicate that psychosocial risks pose a challenge to the mental well-being of their employees in the Region. The results indicated high scores on workrelated stress and burn-out as well as highlighted a number of significant relationships between various psychosocial risks and stress, burn-out and work-family conflict. The findings also highlighted the positive role of management and co-worker support, rewards, possibilities for development and trust (with management as well as with colleagues) as important in mitigating the impact of psychosocial risks.

Although, as mentioned, the results of this risk assessment need to be interpreted with caution, they may be taken into consideration in the development of interventions aimed at enhancing the sense of psychological well-being of staff, initially through actions at the employee level. Staff training material, information leaflets, and provision for further support to manage the impact of psychosocial risks at the workplace need to be tailored to the context of the Organization's occupational sector, a prerequisite for any intervention to be successful [23]. The findings may also be taken into consideration in any proposals aimed at developing a more comprehensive organizational strategy to prevent and manage psychosocial risks at the workplace, a strategy which would eventually be incorporated within the organizational health and safety policy.

Lastly, since psychosocial risks within the context of an organization are dynamic and an ever-changing phenomenon, both the organizational context and the respective programmes need to be continually evaluated and reviewed in order to maintain and improve employee health and well-being [17]. 


\section{References}

1. Basic Documents, 43rd edition, Geneva, World Health Organization, 2001.

2. Healthy workplaces: a model for action: for employers, workers, policymakers and practitioners. Geneva, World Health Organization, 2010

3. Psychosocial factors at work: recognition and control. Geneva, International Labour Organization, 1986 (Occupational Safety and Health Series No. 56)

4. Leka S, Griffiths A, Cox T. Work organization and stress. Geneva, World Health Organization, 2003 (Protecting Workers' Health Series No. 3)

5. Cox T, Griffiths A. The nature and measurement of workrelated stress. In: Wilson J, Corlett N, eds. Evaluation of human work: a practical ergonomics methodology, 3rd ed. Boca Raton, Florida, CRC Press, 2005.

6. European Commission. Guidance on work-related stress-Spice of life or kiss of death? Luxembourg, Office for Official Publications of the European Communities, 2000.

7. Di Martino V, Musri M. Guidance for the prevention of stress and violence at the workplace. Geneva, International Labour Organization, 2001.

8. European Agency of Safety and Health at Work. Expert forecast on emerging psychosocial risks related to occupational safety and health. European Risk Observatory Report. Luxembourg, Office for Official Publications of the European Communities, 2007.

9. Levi L. Spice of life or kiss of death. In: Working on stress. Luxembourg, Office for Official Publications of the European Communities, 2002 (Magazine of the European Agency of Safety and Health at Work, No.5).

10. Koukoulaki T. Stress prevention in Europe: trade union activities. In: lavicoli S. ed. Stress at work in enlarging Europe. Rome, National Institute for Occupational Safety and Prevention, 2004.

11. Van Vegchel $\mathrm{N}$ et al. Reviewing the effort-reward imbalance model: drawing up the balance of 45 empirical studies. Social Science \& Medicine, 2005, 60(5):1117-1131.

12. Cox T, Griffiths A, Rial-Gonzalez E. Research on work related stress. Luxembourg, Office for Official Publications of the European Communities, 2000.
13. Leka S, Jain, A. Health impact of psychosocial hazards at work: an overview. Geneva, World Health Organization, 2010.

14. European Agency of Safety and Health at Work. Violence and harassment at work. European Risk Observatory Report. Luxembourg, Office for Official Publications of the European Communities, 2010.

15. Houtman I, Jettinghoff K, Cedillo L. Raising awareness of stress at work in developing countries. Geneva, World Health Organization, 2007 (Protecting Workers' Health Series, No. 6).

16. Leka S, Cox T, Zwetsloot G. The European framework for psychosocial risk management (PRIMA-EF). In: Leka S, Cox T, eds. The European framework for psychosocial risk management: PRIMA-EF. Nottingham, I-WHO Publications, 2008.

17. Leka $\mathrm{S}$ et al. Towards the development of a psychosocial risk management toolkit. Nottingham, I-WHO Publications, 2008.

18. Kompier MAJ. Assessing the psychosocial work environment- 'subjective' versus 'objective' measurement. Scandinavian Journal of Work and Environmental Health, 2005, 31(6):405-408.

19. Kristensen TS et al. The Copenhagen Psychosocial Questionnaire-a tool for the assessment and improvement of the psychosocial work environment. Scandinavian Journal of Work and Environmental Health, 2005, 31(6):438-449.

20. Kompier MAJ, Kristensen TS. Organizational work stress interventions in a theoretical, methodological and practical context. In: Dunham J, ed. Stress in the workplace: past, present and future. London and Philadelphia, Whurr, 2001:165-190.

21. Messing K. One-eyed science: occupational health and women workers. Philadelphia, Temple Press, 1998

22. Messing $\mathrm{K}$ et al. Be the fairest of them all: challenges and recommendations for the treatment of gender in occupational health research. American Journal of Industrial Medicine, 2003, 43, 618-629.

23. Giga SI, Cooper, CL, Faragher B. The development of a framework for a comprehensive approach to stress management interventions at work. International Journal of Stress Management, 2003, 10(4):280-296. 